\title{
Contribution of socioeconomic status, stature and birth weight to obesity in Sub-Saharan Africa: cross-sectional data from primary school-age children in Cameroon
}

Lifoter K Navti ${ }^{1,2^{*}}$, Uta Ferrari ${ }^{1,3}$, Emmanuel Tange ${ }^{4}$, Susanne Bechtold-Dalla Pozza ${ }^{1,5}$ and Klaus G Parhofer ${ }^{1,6}$

\begin{abstract}
Background: The pattern of obesity in relation to socioeconomic status is of public health concern. This study investigates whether the association between height and obesity in children is affected by their socioeconomic background. It also explores the relationship between high birth weight and obesity.

Methods: School children, ( $N=557 ; 5$ to 12 years old) were recruited from randomly selected primary schools in a cross-sectional study including 173 rural and 384 urban children in the North West Region of Cameroon. Socioeconomic status (SES) and birth weight were obtained using a self administered questionnaire. Anthropometric measures included height, weight, BMI, waist circumference and percentage body fat. These measures were transformed into age and sex-standardized variables. Then participants were divided according to quartiles of height SDS.
\end{abstract}

Results: The highest frequencies of overweight/obesity (18.8\%), abdominal overweight/obesity (10.9\%) and high body fat/obesity (12.3\%) were observed among the tallest children from a high socioeconomic background. Univariate analyses indicate that children of high SES (39.9\%), fourth height quartile (33.1\%) and of high birth weight $(54.8 \%)$ were significantly $(p<0.001)$ more likely to be overweight/obese. Multivariate analyses showed high SES (OR 8.3, 95\% Cl 3.9 - 15.4), fourth height quartile (OR 9.1, 95\% Cl 3.4 - 16.7) and high birth weight (OR 0.1, $95 \% \mathrm{Cl} 0.06-0.2$ ) as independent predictors of overweight/obesity.

Conclusions: This study confirms that children coming from a high socioeconomic background and being tall are at particular risk of becoming obese.

Keywords: Socioeconomic status, Obesity, Height, Children

\section{Background}

The escalating numbers of children affected with overweight and obesity remains a global challenge [1]. This has continued to be a mounting concern among researchers as studies using different obesity parameters have shown that obesity increases the risk of adverse health outcomes including cardiovascular diseases [2], certain cancers, psychological problems and diabetes [3].

\footnotetext{
* Correspondence: Lifoter.Navti@|rz.uni-muenchen.de

${ }^{1} \mathrm{CIH}^{\mathrm{LMU}}$ Center for International Health at Ludwig-Maximilians-Universitaet, Munich, Germany

2Department of Biochemistry, Catholic University of Cameroon (CATUC), P.O Box 782, Bamenda, Cameroon

Full list of author information is available at the end of the article
}

Many studies have identified different factors that could explain to various extents the current dramatic global increase in the prevalence of overweight and obesity, which include: decreased physical activity [4], food marketing practices [5], genetic influence [6,7], maternal smoking during pregnancy [8], high birth weight [9], increased television viewing [10], higher dietary energy density [11], parental obesity [12] and more. Additionally, a review had indicated the contribution of socioeconomic background to social inequalities in the distribution of the frequency of obesity [13]. This indicates that overweight and obesity involves a complex interaction between many variables in childhood, adulthood and old age. The 
majority of the studies above have been carried out in developed countries.

Sub-Saharan African countries including Cameroon are at various stages of economic development. Because of the increased attention gained by social inequalities in health, the close monitoring of the socioeconomic pattern of obesity especially among school children [14] in this region is important. There has been little attention to this group of children and if nothing is done, this might pose a major human and economic cost to this region in the future and might affect the sustainability of the healthcare systems, which are already over burdened with high rates of infectious diseases.

In developing economies, overweight and obesity tends to affect more people from a high socioeconomic background $[14,15]$. In contrast, in developed nations obesity is inversely related to socioeconomic status (SES), a situation which is more pronounced in women [16]. This inverse relationship has also been confirmed in children $[17,18]$, with parental social class contributing to offspring obesity [19].

There is evidence indicating that children from a low income group were significantly shorter than those from a high income group and regardless of the income background, overweight and obese children were taller than their non-overweight and non-obese peers [20]. Even though it is documented that increased height among children is associated with increased risk of obesity [21-23], evidence from Chile during the nutrition transition shows that both tallness and stunting in children are associated to obesity [24].

High birth weight has also been documented as an indicator for later obesity. For instance, some studies $[9,25,26]$ have shown a positive association between high birth weight and obesity later in life. However, a cohort study did not find any association between birth weight and adult body mass index [27].

The aim of this study is to explore the interactions between SES, height and obesity and test the hypothesis that the height-obesity association is greater in schoolage children from a high socioeconomic background. It also explores the relationship between high birth weight and overweight/obesity.

\section{Methods}

\section{Subjects}

The data used in this study were collected crosssectionally between February and June 2012, from children living and attending primary education in the North West Region of Cameroon including a mix of socioeconomic groups from rural and urban populations. The analyses consisted of 557 participants (173 from rural and 384 from urban settings) of ages 5 to 12 years and were recruited from both private and public schools selected at random. Consent information, which explained the purpose of the study, was distributed in the schools to parents or guardians and the head teachers accompanied by the study questionnaire. Also, the principal investigator (L.K.N) had the opportunity to explain the aims of the study to parents or guardians during the Parents Teachers Association (PTA) meetings, which usually take place within the academic year. In return a signed informed consent certificate was obtained from each parent or guardian and school head teacher before measurements were carried out. Dates of birth and gender were collected from school records at the same time as the anthropometric measurements.

\section{Anthropometry}

All measurements were school-based and conducted by well trained nurses ensuring that standard protocols were respected. Assent was obtained from each participant before measurements. Standing height was measured close to $0.1 \mathrm{~cm}$ without shoes using a portable stadiometer (Seca 213, Germany). A digital scale (Omron BF 511, Japan) was used to measure body weight to the nearest $0.1 \mathrm{~kg}$ with children dressed in light school uniforms and shoes taken off. Then height and weight were used to calculate body mass index $\left(\mathrm{kg} / \mathrm{m}^{2}\right)$ as a general measure of weight status.

Waist circumference, a measure of abdominal fatness, was measured as recommended by McCarthy et al. [28] using a non-elastic flexible tape (Seca 201, Germany).

The formula of Deurenberg et al. was used to estimate percentage body fat in children. $\% \mathrm{BF}=1.51 \times \mathrm{BMI}-$ $0.70 \times$ age $-3.6 \times$ sex +1.4 ( where males $=1$, females $=0$ ). This formula has been validated elsewhere [29].

\section{Socioeconomic status}

The Cameroon classification system of occupation and income; civil servants categories $\mathrm{C}, \mathrm{B}$ and $\mathrm{A}$ of the public service, was used to categorize participants into low, middle and high socioeconomic status (SES) respectively [15]. This information was obtained from parents or guardians whose children participated in the study using a structured questionnaire designed in English and French. The highest level of SES of either parent was used to assign each child to the appropriate category of SES. Parental level of education was also assessed using the questionnaire and four categories were established: illiterate (attended no school), primary ( $1-6$ years of education), secondary (7 - 13 years of education) and higher education ( $>13$ years of education). The categorization of participants was based on the parent with the highest level of education. SES levels were obtained from 522 out of the 557 parents giving a response rate of $93.7 \%$. Also, a response rate of $89.05 \%$ was obtained for parental level of education. 


\section{Birth weight}

Birth weight was self reported by parents on the questionnaire and in the analysis high birth weight was indicated as birth weight $>4 \mathrm{~kg}$. These readings were obtained from 454 parents giving a response rate of $81.5 \%$.

\section{Ethical and administrative clearances}

Approval for this study was obtained from the Institutional Review Board of the Biotechnology Center of the University of Yaoundé I. Administrative clearances were obtained from the Regional Delegation for Public Health and the Regional Delegation for Basic Education of the North West Region of Cameroon. All parents gave written informed consent before any study related procedure was performed.

\section{Statistical analysis}

SPSS for Windows version 16.0 was used for analyses. Height, weight and BMI were converted to their corresponding standard deviation scores (SDS) using the WHO growth reference data [30]. Also, waist circumference and percentage body fat were standardized for age and sex using the UK reference data for waist circumference [28] and percentage body fat [31]. The study participants were sorted according to increasing height SDS and then divided into quartiles of height SDS. The mean height and weight SDSs were also compared across the socioeconomic groups using a 1-way ANOVA with post hoc Bonferroni test. A parametric $t$ test was used to compare means of age-adjusted and unadjusted anthropometric measures between boys and girls.

Overweight and obesity were defined using the WHO cut-off points [30], while the 91st percentile [28] was used to define abdominal overweight/obesity and the 85th percentile [31] used for high body fat/obesity.

In addition, the frequencies of overweight/obesity, abdominal overweight/obesity and high body fat/obesity stratified by SES, quartiles of height SDS, and high birth weight (determinants) were calculated. This was followed by univariate analysis, which was done using binary logistic regression models to estimate the corresponding odds ratios (OR) (adjusted for age and gender) with 95\% CI and $p$-values. Further, multivariate binary logistic regression analysis was performed to determine the independent association between each of the determinants and the obesity measures. SES, height SDS and birth weight showed significant associations with obesity in the univariate analysis and were included in the model as well as age and gender during the multivariate analysis.

Moreover, height SDS showed significant interactions with SES in this study. Therefore, the frequencies of overweight/obesity, abdominal overweight/obesity and high body fat/obesity according to quartiles of height SDS differentiated by the socioeconomic groups were estimated. A $p$-value of 0.05 was used to indicate statistical significance.

\section{Results}

There were significant differences $(p<0.05)$ in BMI SDS, WC SDS and \%BF between boys and girls in this study. Table 1 shows the main characteristics of the study population $(\mathrm{N}=557), 48.5 \%$ were female and $51.5 \%$ were male. $31.1 \%$ of the subjects were from the rural areas whereas $68.9 \%$ from urban areas. Less than $30 \%$ of the participants were from the middle or high socioeconomic background. More girls than boys were categorized as overweight or obese on the basis of waist circumference or percentage body fat.

Also, Table 2 shows that obesity was more pronounced among urban girls than boys when all three parameters of obesity were used.

Univariate analysis in Table 3 show that regardless of which measure of obesity used, a high socioeconomic background, tallness and a high birth weight were significantly associated with a higher frequency of overweight/obesity, abdominal overweight/obesity and high body fat/obesity after adjusting for age and gender. This association was more pronounced when BMI is used as a measure of obesity. However, parental level of education did not show any significant association with the parameters of obesity in univariate analysis.

The results of the multivariate analysis are shown on Table 4. The model showed a statistically significant independent association between overweight/obesity, abdominal overweight/obesity and high body fat/obesity and SES, height SDS and high birth weight.

Figure 1 shows that participants from the high socioeconomic background were significantly $(p<0.001)$ taller than those from the low socioeconomic group, which corresponds to a 0.6 unit difference in height SDS. However, there were no significant differences in height SDS between the low and middle SES groups and also between the middle and high SES groups after carrying out a 1-way ANOVA with post hoc Bonferroni test.

Based on the significant difference in height observed between the low and high SES group, Table 5 shows the frequency of excess body fat tabulated in the three socioeconomic groups and quartiles of height SDS. It indicates that the frequencies of overweight/ obesity, abdominal overweight/obesity and high body fat/obesity were highest among the tallest children from the high socioeconomic group. Also, in the second, third and fourth quartiles of height SDS, there was a progressive increase in the frequency of obesity with increasing SES. In this study, weight SDS also differed significantly within the socioeconomic groups. 
Table 1 Descriptive characteristics by gender, $n[\%(95 \% \mathrm{CI})]$, mean age $9.0 \pm 1.8$ years

\begin{tabular}{|c|c|c|c|c|c|c|}
\hline \multirow{3}{*}{ Variables } & \multirow{2}{*}{\multicolumn{3}{|c|}{$\begin{array}{c}\text { Girls } \\
N=270\end{array}$}} & \multirow{2}{*}{\multicolumn{3}{|c|}{$\begin{array}{c}\text { Boys } \\
N=287\end{array}$}} \\
\hline & & & & & & \\
\hline & $\mathbf{n}$ & \multicolumn{2}{|r|}{$[\%(95 \% \mathrm{Cl})]$} & $\mathbf{n}$ & \multicolumn{2}{|r|}{$[\%(95 \% \mathrm{Cl})]$} \\
\hline Rural & 83 & 30.7 & $(25.5-36.5)$ & 90 & 31.4 & $(26.2-36.9)$ \\
\hline Urban & 187 & 69.3 & $(61.3-76.7)$ & 197 & 68.6 & $(63.0-73.8)$ \\
\hline \multicolumn{7}{|l|}{ Socioeconomic status } \\
\hline Low & 117 & 43.3 & $(37.6-49.2)$ & 123 & 42.9 & $(37.3-48.7)$ \\
\hline Middle & 70 & 25.9 & $(21.0-31.5)$ & 74 & 25.8 & $(21.1-31.1)$ \\
\hline High & 73 & 27.0 & $(22.1-32.6)$ & 65 & 22.6 & $(18.2-27.8)$ \\
\hline Missing data & 10 & 3.7 & - & 25 & 8.7 & - \\
\hline \multicolumn{7}{|l|}{ Body mass index ${ }^{a}$} \\
\hline Thinness & 5 & 1.9 & $(0.7-4.4)$ & 1 & 0.3 & $(0.0-1.9)$ \\
\hline Normal & 219 & 81.1 & $(75.6-85.0)$ & 235 & 81.9 & $(77.0-85.9)$ \\
\hline Overweight and obesity & 46 & 17.0 & $(12.9-22.0)$ & 51 & 17.8 & $(12.1-24.7)$ \\
\hline \multicolumn{7}{|l|}{ Waist circumference ${ }^{b}$} \\
\hline Small & 2 & 0.7 & $(0.2-2.7)$ & 3 & 1.0 & $(0.3-3.1)$ \\
\hline Normal & 220 & 81.5 & $(74.8-87.0)$ & 256 & 89.2 & $(80.2-98.5)$ \\
\hline Abdominal overweight and obesity & 48 & 17.8 & $(11.8-25.1)$ & 28 & 9.8 & $(7.1-14.0)$ \\
\hline \multicolumn{7}{|l|}{ Percentage body fat ${ }^{\mathrm{b}}$} \\
\hline Low & 8 & 3.0 & $(1.5-5.7)$ & 3 & 1.0 & $(0.4-3.0)$ \\
\hline Normal & 220 & 81.5 & $(76.4-85.7)$ & 268 & 93.4 & $(89.9-95.7)$ \\
\hline High body fat and obesity & 42 & 15.5 & $(11.7-20.4)$ & 16 & 5.6 & $(3.5-8.9)$ \\
\hline
\end{tabular}

\section{Discussion}

This study set out firstly to examine the effect of socioeconomic background on the relationship between height SDS and three measures of obesity, and secondly to determine the relationship between high birth weight and obesity in children.

It was demonstrated that the frequency of excess body fat was highest among the tallest children in the high socioeconomic group. Also, the study confirmed from the multivariate analyses that high SES, tallness, and high birth weight were strong independent predictors of obesity. This was consistent for all three parameters of obesity.
A recent study among adults in urban Cameroon showed a positive association between obesity and SES [15]. This has been attributed to the current nutrition transition experienced in Sub-Saharan countries. As the economies and peoples' earnings are getting better, they tend to adopt Western lifestyles decreasing their physical activity levels $[32,33]$. A shift in dietary pattern from fruits, vegetables and grains to an increased intake of animal fats, sugar and salt as a result of better income has also been attributed to the rise in obesity levels in developing countries [5]. These lifestyle changes are reflected in Cameroon children and could explain why some of them accumulate more body fat.

Table 2 Prevalence of excess body fat in relation to degree of urbanization

\begin{tabular}{|c|c|c|c|c|c|}
\hline & \multirow{2}{*}{ Gender } & \multicolumn{2}{|c|}{ Urban } & \multicolumn{2}{|c|}{ Rural } \\
\hline & & $\%$ & $(95 \% \mathrm{Cl})$ & $\%$ & $(95 \% \mathrm{Cl})$ \\
\hline \multirow{2}{*}{ Overweight/obesity (BMI) } & Boys & 17.8 & $(13.1-23.7)$ & 17.7 & $(11.3-26.9)$ \\
\hline & Girls & 18.2 & $(13.3-24.3)$ & 14.5 & $(8.5-23.6)$ \\
\hline \multirow{2}{*}{ Abdominal overweight/obesity (WC) } & Boys & 10.2 & $(6.5-15.2)$ & 8.9 & $(4.6-16.6)$ \\
\hline & Girls & 20.9 & $(15.7-27.2)$ & 10.8 & $(5.8-19.3)$ \\
\hline \multirow{2}{*}{ High body fat/obesity (\%BF) } & Boys & 6.6 & $(3.9-11.0)$ & 3.3 & $(1.1-9.4)$ \\
\hline & Girls & 17.6 & $(12.9-23.8)$ & 10.8 & $(5.8-19.3)$ \\
\hline
\end{tabular}

Cl: confidence interval 
Table 3 Frequency and OR $(95 \% \mathrm{Cl})$ for the association of excess body fat with potential determinants

\begin{tabular}{|c|c|c|c|c|c|c|c|c|c|c|}
\hline \multirow{2}{*}{ Determinants } & \multirow{2}{*}{$\underset{557}{N}$} & \multicolumn{3}{|c|}{ Overweight/obesity (BMI) } & \multicolumn{3}{|c|}{ Abdominal overweight/obesity (WC) } & \multicolumn{3}{|c|}{ High body/obesity (\%BF) } \\
\hline & & 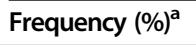 & OR (95\% Cl) & $p$-value & Frequency (\%) & OR $(95 \% \mathrm{Cl})$ & $p$-value & ${\text { Frequency }(\%)^{c}}^{c}$ & OR $(95 \% \mathrm{Cl})$ & $p$-value \\
\hline \multicolumn{11}{|l|}{ Socioeconomic status } \\
\hline High & 138 & 39.9 & $10.1(5.4-18.9)$ & $<0.001$ & 26.1 & $3.5(1.9-6.2)$ & $<0.001$ & 23.2 & $0.2(0.1-0.5)$ & $<0.001$ \\
\hline Medium & 144 & 16.0 & $3.5(2.0-6.2)$ & $<0.001$ & 11.1 & $2.8(1.5-5.3)$ & 0.002 & 9.0 & $0.1(0.05-0.3)$ & $<0.001$ \\
\hline Low & 240 & 6.3 & ref. & & 9.2 & ref. & & 4.6 & ref. & \\
\hline Missing data & 35 & & & & & & & & & \\
\hline \multicolumn{11}{|l|}{$\begin{array}{l}\text { Quartiles of height } \\
\text { SDS }\end{array}$} \\
\hline Fourth quartile & 139 & 33.1 & $10.9(4.6-25.8)$ & $<0.001$ & 30.2 & $4.2(2.2-8.2)$ & $<0.001$ & 23.7 & $0.3(0.1-0.7)$ & 0.006 \\
\hline Third quartile & 137 & 20.4 & $2.3(1.3-4.0)$ & 0.004 & 12.4 & $3.8(2.0-7.2)$ & $<0.001$ & 8.0 & $0.3(0.1-0.7)$ & 0.007 \\
\hline Second & 141 & 19.1 & $3.6(1.9-6.6)$ & $<0.001$ & 11.3 & ref. & & 7.8 & $0.1(0.03-0.4)$ & $<0.001$ \\
\hline First & 140 & 5.0 & ref. & & 0.7 & & & 2.1 & ref. & \\
\hline \multicolumn{11}{|l|}{$\begin{array}{l}\text { High birth weight } \\
(>4 \mathrm{~kg})\end{array}$} \\
\hline Yes & 95 & 54.8 & $8.7(5.2-14.5)$ & $<0.001$ & 34.7 & $5.2(2.9-9.1)$ & $<0.001$ & 27.4 & $7.1(3.5-14.7)$ & $<0.001$ \\
\hline No & 359 & 12.3 & ref. & & 9.7 & ref. & & 7.0 & ref. & \\
\hline Missing data & 103 & & & & & & & & & \\
\hline
\end{tabular}

abc Based on WHO 2007 BMI, UK $199091^{\text {st }}$ centile and UK $199085^{\text {th }}$ centile cut-offs respectively. Abbreviations: OR. Odds ratio; Cl, confidence interval. (odds ratios adjusted for age and gender). Overweight/obesity, abdominal overweight/obesity and high body fat/obesity are defined by BMl, waist circumference and\% body fat respectively.

Another study in urban Cameroon had indicated that the prevalence of overweight was high among adolescents from all socioeconomic groups; the low (8\%), middle (11\%) and high (9\%), with girls more likely to be overweight than boys [34]. Our study has also found a higher frequency of excess body fat among urban girls. In addition to the latter, our study has demonstrated the existence of a much more pronounced SES gradient in the distribution of the prevalence of excess body fat in school age children. More children from the high socioeconomic background are affected than their peers from the low socioeconomic group. Even though there is no documented evidence, in the past, children used to walk to school, an activity that burnt lots of calories in children. However, motorized transportation to schools nowadays, a common phenomenon in urban settings, which is easily affordable by parents of a higher socioeconomic status, could contribute to some extent in

Table 4 Multivariate binary logistic regression analysis with overweight/obesity (BMI), abdominal overweight/obesity (WC) and high body fat/obesity (\%BF) as dependent variable

\begin{tabular}{|c|c|c|c|c|c|c|}
\hline & \multicolumn{2}{|c|}{ Overweight/obesity (BMI) } & \multicolumn{2}{|c|}{ Abdominal overweight/obesity (WC) } & \multicolumn{2}{|c|}{ High body fat/obesity (\%BF) } \\
\hline & OR $(95 \% \mathrm{Cl})$ & $p$-value & OR $(95 \% \mathrm{Cl})$ & $p$-value & OR $(95 \% \mathrm{Cl})$ & $p$-value \\
\hline \multicolumn{7}{|l|}{ Socioeconomic status } \\
\hline High & $8.3(3.9-15.4)$ & $<0.001$ & $2.5(1.2-5.6)$ & 0.017 & $0.2(0.1-0.6)$ & 0.003 \\
\hline Medium & $3.7(1.8-7.3)$ & $<0.001$ & $2.1(1.8-7.3)$ & $<0.001$ & $0.1(0.05-0.4)$ & $<0.001$ \\
\hline Low & ref. & & ref. & & ref. & \\
\hline \multicolumn{7}{|c|}{ Quartiles of height SDS } \\
\hline Fourth quartile & $9.1(3.4-16.7)$ & $<0.001$ & $4.1(1.9-8.7)$ & $<0.001$ & $0.3(0.1-0.7)$ & 0.010 \\
\hline Third quartile & $2.1(1.0-4.1)$ & 0.041 & $3.8(1.8-8.1)$ & $<0.001$ & $0.4(0.2-0.9)$ & 0.041 \\
\hline Second & $3.7(1.7-7.9)$ & 0.001 & ref. & & $0.2(0.05-0.7)$ & 0.014 \\
\hline First & ref. & & & & ref. & \\
\hline \multicolumn{7}{|c|}{ High birth weight (>4 kg) } \\
\hline Yes & $0.1(0.06-0.2)$ & $<0.001$ & $0.2(0.1-0.4)$ & $<0.001$ & $7.1(3.2-15.9)$ & $<0.001$ \\
\hline No & ref. & & ref. & & ref. & \\
\hline
\end{tabular}

OR, odds ratio; $\mathrm{Cl}$, confidence interval; (odds ratios adjusted for age and gender). Overweight/obesity, abdominal overweight/obesity and high body fat/obesity are defined by BMI, waist circumference and\% body fat respectively. 


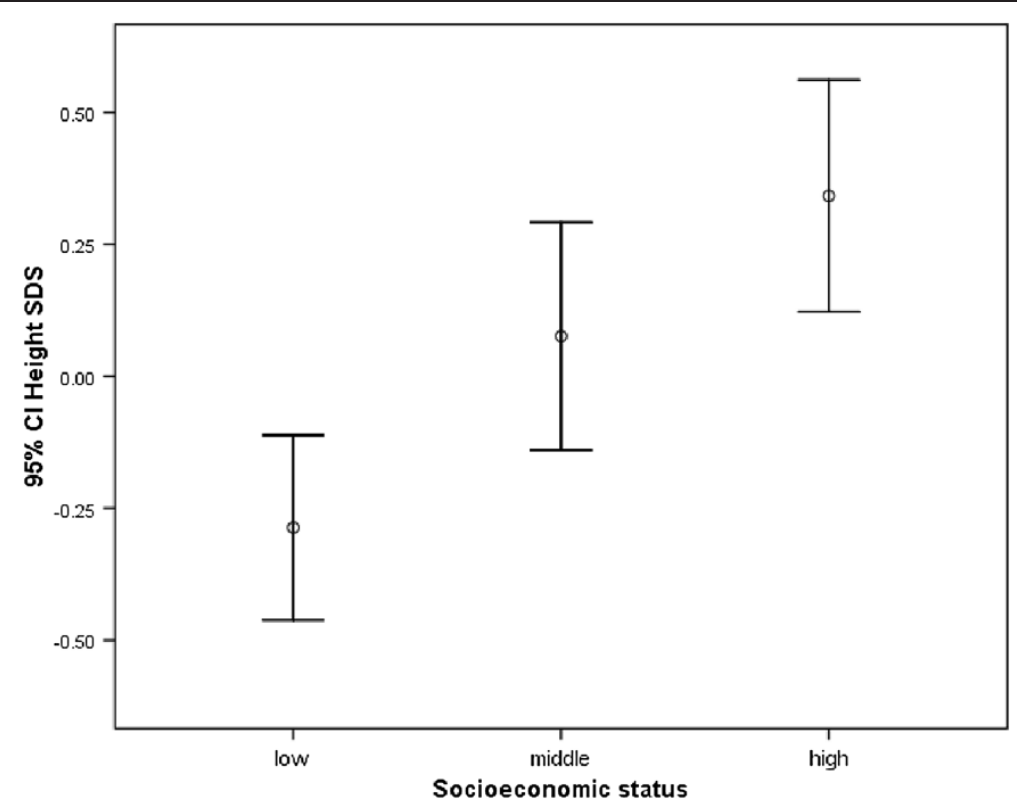

Figure 1 Height differences by socioeconomic status. Significant difference observed between low and high SES $(p<0.001)$. N = 522 after exclusion of subjects with no information on SES.

lowering physical activity levels in children. Also children now spend more hours in sedentary activities like television watching, which has been associated to overweight and obesity in developed countries [35-37]. However, in relation to income group, studies in the developed world have shown that overweight and obesity affects mostly people from disadvantaged groups $[18,20,38]$.
Children from the high SES group were significantly taller than those from the low SES group. A recent study made a similar observation and described this situation to be 'largely associated to a relative height-growth restriction' [20]. However, in our study, age and sex-adjusted weight was also significantly different in the socioeconomic groups, meaning that overall weight could also

Table 5 Frequency of excess body fat according to quartiles of height SDS differentiated by socioeconomic status

\begin{tabular}{|c|c|c|c|c|c|c|}
\hline \multirow{3}{*}{ Quartiles of height SDS } & \multicolumn{6}{|c|}{ Socioeconomic status } \\
\hline & \multicolumn{2}{|c|}{ Low } & \multicolumn{2}{|c|}{ Middle } & \multicolumn{2}{|c|}{ High } \\
\hline & $\%$ & $\overline{(95 \% \mathrm{Cl})}$ & $\%$ & $(95 \% \mathrm{Cl})$ & $\%$ & $(95 \% \mathrm{Cl})$ \\
\hline \multicolumn{7}{|l|}{ Overweight/obesity (BMI) } \\
\hline First quartile & 1.3 & $(0.4-3.6)$ & 2.1 & $(0.7-6.0)$ & 0.7 & $(0.1-4.0)$ \\
\hline Second quartile & 1.7 & $(0.7-4.2)$ & 4.2 & $(1.9-8.9)$ & 10.1 & $(6.1-16.3)$ \\
\hline Third quartile & 0.8 & $(0.2-3.0)$ & 1.4 & $(0.4-4.9)$ & 10.1 & $(6.1-16.3)$ \\
\hline Fourth quartile & 2.5 & $(1.2-5.4)$ & 7.6 & $(4.3-13.2)$ & 18.8 & $(13.2-26.2)$ \\
\hline \multicolumn{7}{|c|}{ Abdominal overweight/obesity (WC) } \\
\hline First quartile & 0.0 & $(0.0-1.6)$ & 0.7 & $(0.1-3.8)$ & 0.0 & $(0.0-2.7)$ \\
\hline Second quartile & 1.3 & $(0.4-3.6)$ & 1.4 & $(0.4-4.9)$ & 7.3 & $(4.0-12.8)$ \\
\hline Third quartile & 1.3 & $(0.4-3.6)$ & 2.1 & $(0.7-6.0)$ & 8.0 & $(4.5-13.7)$ \\
\hline Fourth quartile & 6.7 & $(4.1-10.6)$ & 6.9 & $(3.8-12.3)$ & 10.9 & $(6.7-17.2)$ \\
\hline \multicolumn{7}{|l|}{ High body fat/obesity (\%BF) } \\
\hline First quartile & 0.8 & $(0.2-3.0)$ & 0.0 & $(0.0-2.6)$ & 0.7 & $(0.1-4.0)$ \\
\hline Second quartile & 1.3 & $(0.4-3.6)$ & 1.4 & $(0.4-4.9)$ & 4.4 & $(2.0-9.2)$ \\
\hline Third quartile & 0.0 & $(0.0-1.6)$ & 2.1 & $(0.7-6.0)$ & 5.8 & $(3.0-11.0)$ \\
\hline Fourth quartile & 2.5 & $(1.2-5.4)$ & 5.6 & $(2.8-10.6)$ & 12.3 & $(7.8-18.8)$ \\
\hline
\end{tabular}

$\mathrm{N}=522$ after exclusion of subjects with no information on $\mathrm{SES} ; \mathrm{Cl}$, confidence interval. 
have contributed to the high prevalence of excess body fat among children from the high SES group.

The high prevalence of obesity among subjects from a high SES could also be explained by the fact that food preparation patterns have changed over time with homemade foods gradually being replaced by more convenient and high calorie ready to eat foods [5] especially in urban areas. Also, historically, children used to take home made lunch to school. Nowadays, high income earners prefer to give pocket allowances to children who will spend it on high sugar containing snacks sold near school premises. In addition, children are a target to the advertisement of fizzy drinks and confectioneries [5], which are easily afforded by the rich parents in developing economies. No dietary information was obtained from the children in this study to substantiate the above points. In fact, a study indicated the potential of poor nutrition and decreased physical activity to induce obesity and linear growth in children [20].

Our study has shown a significant relation between height SDS and obesity. Similar findings have been indicated in other studies [22,23]. Possible reasons for this relationship include a hormonal imbalance between insulin-like growth factor 1 and growth hormone [39] and early high protein intake [40]. The source of protein is still a subject of debate. High birth weight was also associated to obesity in both univariate and multivariate analyses. A review indicated that high birth weight is associated to higher obesity levels in adulthood [41].

This study did not find any association between parental level of education and the different parameters of obesity in the children. Similarly, a study in urban Cameroon did not find any significant association between obesity and level of education in adults [15]. The authors indicated that this reflects the Cameroon society of today where a better education is not necessarily associated to a higher salary. Those involved in financially rewarding economic activities are often the less educated [15].

This study had limitations worth mentioning. Birth weight was not available for all participants and bias could have been possible as birth weight was self reported by parents. Also, the tanner stages of children were not estimated and early puberty could have affected the height-obesity relationship especially among girls who had higher $\mathrm{WC}$ and \%BF readings. This study made use of UK references for WC and percentage body fat and it is unclear if these references can be applied to our study population. Percentage body fat was predicted from an equation that was validated in a study in Europe and it is not certain if this can be applied to this study. Further, the influence of genetics on height cannot be completely ruled out. This study used parental occupation, income and level of education as indicators of the SES of participants. However, a study in urban Cameroon has shown the World Bank household amenities score as a better indicator for SES in developing economies [15]. Information on SES was not available for all subjects in this study. It is possible that some of the parents considered this as confidential information or were unwilling to confide as to what may happen with this information [15]. This study used the Cameroon public service classification system which does not adequately reflect the socioeconomic background of those in the private sector as well as housewives at any one moment. Finally, the limited number of children with excess body fat in this study did not permit us to examine if the associations differed by sex.

Despite the above limitations, this study has provided data for the first time for Cameroon to examine the height-obesity-SES interactions in school children (a group usually neglected in health surveys). Another positive aspect of this study was the high response rate of 93.7 and 81.5 and $89.05 \%$ for SES, birth weight and parental level of education respectively. In addition to BMI, this study has used WC and \%BF, which provide information on body fat distribution.

\section{Conclusion}

Concluding this study in Sub-Saharan African children shows an association between a high frequency of obesity and tall stature with high socioeconomic status. This implies that any future obesity prevention program in the North West Region of Cameroon will need to start at the family level beginning with individuals of a high socioeconomic background (especially in urban settings). However, the effect of socioeconomic background on height-obesity relationship in school age children needs further exploitation using a more accurate indicator of SES like household amenities in other regions of Cameroon and Africa.

\section{Competing interests}

The authors declare that they have no competing interests.

\section{Authors' contributions}

LKN was responsible for the conception and design of the study, direct collection of data and organization, statistical analysis and drafted the manuscript. UF contributed to the conception and the design of the study as well as interpretation and analysis concepts of data. ET contributed to the design of the study, participated in data collection and contributed to drafting of the manuscript. SBD contributed to the conception and design of the study, data interpretation and drafting of the manuscript. KGP substantially contributed to the conception and design of the study, participated in data collection as well as interpretation of data. All authors revised the manuscript and gave a final approval of the submitted version.

\section{Acknowledgements}

We are grateful to the nurses, head teachers of the different schools, the parents and children who accepted to participate in this study. LKN acknowledges receipt of a scholarship from the Center for International Health at Ludwig-Maximilians-Universitaet, Munich, Germany, funded by the German Academic Exchange Service (DAAD) and the German Federal Ministry for Economic Cooperation and Development (BMZ). 


\section{Author details}

${ }^{1} \mathrm{CIH}^{\mathrm{LMU}}$ Center for International Health at Ludwig-Maximilians-Universitaet, Munich, Germany. ${ }^{2}$ Department of Biochemistry, Catholic University of Cameroon (CATUC), P.O. Box 782, Bamenda, Cameroon. ${ }^{3}$ Diabetes Research Group, Department of Medicine IV, Ludwig-Maximilians-Universitaet, Ziemssenstr. 1, Munich 80336, Germany. ${ }^{4}$ Department of Food Science and Technology, Catholic University of Cameroon (CATUC), P.O. Box 782, Bamenda, Cameroon. ${ }^{5}$ Pediatric Endocrinology and Diabetology, University Children's Hospital, Ludwig-Maximilians-Universitaet, Lindwurmstr. 4 Munich 80337, Germany. 'Department of Medicine II - Grosshadern, Ludwig-Maximilians-Universitaet, Marchioninistr. 15, Munich 81377, Germany.

Received: 8 February 2014 Accepted: 5 April 2014

Published: 7 April 2014

\section{References}

1. Jafar TH, Qadri Z, Islam M, Hatcher J, Bhutta ZA, Chaturvedi N: Rise in childhood obesity with persistently high rates of undernutrition among urban school-age Indo-Asian children. Arch Dis Child 2008, 93:373-378.

2. Geiss HC, Parhofer KG, Schwandt P: Parameters of childhood obesity and their relationship to cardiovascular risk factors in healthy prepubescent children. Int J Obes 2001, 25:830-837.

3. World Health Organization: Preventing and Managing the Global Epidemic, WHO Technical Report Series No. 894. Geneva: World Health Organization; 2000.

4. Trost SG, Sirard JR, Dowda M, Pfeiffer KA, Pate RR: Physical activity in overweight and non-overweight preschool children. Int J Obes 2003, 27:834-839.

5. Witkowski TH: Food marketing and obesity in developing countries: analysis, ethics, and public policy. J Macromarketing 2007, 27:126-137.

6. Hardy R, Wills AK, Wong A, Elks CE, Wareham NJ, Loos RJ, Kuh D, Ong KK: Life course variations in the associations between FTO and MC4R gene variants and body size. Hum Mol Genet 2010, 19:545-552.

7. Wardle J, Carnell S, Haworth MA, Plomin R: Evidence for a strong genetic influence on childhood adiposity despite the force of the obesogenic environment. Am J Clin Nutr 2008, 87:398-404.

8. Oken E, Levitan EB, Gillman MW: Maternal smoking during pregnancy and child overweight: systematic review and meta-analysis. Int J Obes 2008, 32:201-210.

9. Eriksson J, Forsen T, Tuomilehto J, Osmond C, Barker D: Size at birth childhood growth and obesity in adult life. In J Obes Relat Metab Disord 2001, 25:735-740.

10. Crespo CJ, Smith E, Troiano RP, Bartlett SJ, Macera CA, Andersen RE: Television watching, energy intake, and obesity in US children: results from the third National Health and Nutrition Examination Survey, 1988-1994. Arch Pediatr Adolesc Med 2001, 155:360-365

11. Johnson L, Mander AP, Jones LR, Emmett PM, Jebb SA: A prospective analysis of dietary energy density at age 5 and 7 years and fatness at 9 years among UK children. Int J Obes 2008, 32:586-593.

12. Kumar S, Raju M, Gowda N: Influence of parental obesity on school children. Indian J Pediatr 2010, 77:255-258.

13. Monteiro CA, Moura EC, Conde WL, Popkin BM: Socioeconomic status and obesity in adult populations of developing countries: a review. Bull World Health Organ 2004, 82:940-946.

14. McLaren L: Socioeconomic status and obesity. Epidemiology Rev 2007, 29:29-48.

15. Fezeu L, Minkoulou E, Balkau B, Kengne AP, Awah P, Unwin N, Alberti GK, Mbanya JC: Association between socioeconomic status and adiposity in urban Cameroon. Int J Epidemiol 2005, 35:105-111.

16. Sobal J, Stunkard AJ: Socioeconomic status and obesity: a review of the literature. Psychol Bull 1989, 105:260-275.

17. Bammann K, Gwozdz W, Lanfer A, Barba G, de Henauw S, Eiben G, Fernandez-Alvira JM, Kovacs E, Lissner L, Moreno LA, Tornaritis M, Veidebaum T, Pigeot I: Socioeconomic factors and childhood overweight in Europe: results from a multi-centre IDEFICS study. Pediatric Obesity 2013, 8:1-12.

18. Stamatakis E, Wardle J, Cole TJ: Childhood overweight and obesity trends in England: evidence for growing socioeconomic disparities. Int J Obes 2010, 34:41-47.

19. Stamatakis E, Primatesta P, Chin S, Rona R, Falascheti E: Overweight and obesity trends from 1973 to 2003 in English children: what is the role of socioeconomic factors? Arch Dis Child 2005, 90:999-1004.

20. Cecil JE, Watt P, Murri IS, Wrieden W, Wallis DJ, Hetherington MM, Bolton-Smith C, Palmer CN: Childhood obesity and socioeconomic status; a novel for height growth limitation. Int J Obes 2005, 29:1199-1203.
21. Stanojevic S, Kain J, Uauy R: The association between changes in height and obesity in Chilean preschool children: 1996-2004. Obesity 2007, 15:1012-1022

22. Freedman DS, Khan LK, Mei Z, Dietz WH, Srinivasan SR, Berenson GS: Relation of childhood height to obesity among adults: The Bogalusa Heart Study. Pediatrics 2002, 309:1-7.

23. Freedman DS, Thornton JC, Mei Z, Wang J, Dietz WH, Pierson RN, Horlick M: Height and adiposity among children. Obes Res 2004, 12:846-853.

24. Kain J, Uauy R, Lera L, Taibo M, Albala C: Trends in height and BMI of 6-year old children during the nutrition transition in Chile. Obes Res 2005, 13:2178-2186.

25. Danielzik S, Czerwinski-Mast M, Langnase K, Dilba B, Muller MJ: Parental overweight, socioeconomic status, and high birth weight are the major determinants of overweight and obesity in 5-7 year old children: baseline data of the kiel obesity prevention (KOPS). Int J Obes Relat Metab Disord 2004, 28:1494-1502.

26. Zhao Y, Wang SF, Mu M, Sheng J: Birth weight and overweight/obesity in adults: a meta-analysis. Eur J Pediatr 2012, 171:1737-1746.

27. McCarthy A, Hughes R, Tilling K, Davies D, Smith GD, Ben-Shlomo Y: Birth weight; postnatal, infant, and childhood growth; and obesity in young adulthood: evidence from the Barry Caerphilly Growth Study. Am J Clin Nutri 2007, 86:907-913.

28. McCarthy HD, Jarrett KV, Crawley HF: The development of waist circumference percentiles in British children aged 5.0 to 16.9y. Eur J Clin Nutr 2001, 55:902-907

29. Deurenberg P, Weststrate JA, Seidell JC: Body mass index as a measure of body fatness: age- and sex-specific prediction formulas. Br J Nutr 1991 65:105-114

30. Borghi E, de Onis M, Garza C, Van den Broeck J, Frongillo EA, Grummer-Strawn L, Van Buuren S, Pan H, Molinari L, Martorell R, Onyango AW, Martines JC: Construction of the World Health Organisation child growth standards: selection of methods for attained growth curves. Statist Med 2006, 25:247-265

31. McCarthy HD, Cole TJ, Fry T, Jebb SA, Prentice AM: Body fat reference curves for children. Int J Obes 2006, 30:598-602.

32. Sobngwi E, Mbanya JCN, Unwin NC, Kengne AP, Fezeu L, Minkoulou EM Aspray TJ, Alberti KGMM: Physical activity and its relationship with obesity, hypertension and diabetes in urban and rural Cameroon. Int J Obes 2002, 26:1009-1016.

33. Fezeu LK, Assah FK, Balkau B, Mbanya DS, Kengne AP, Awah PK, Mbanya JCN: Ten-year changes in central obesity and BMI in rural and urban Cameroon. Obesity 2008, 16:1144-1147.

34. Dapi LN, Janlert U, Nouedoui C, Stenlun H, Haglin L: Socioeconomic and gender differences in adolescents' nutritional status in urban Cameroon, Africa. Nutr Res 2009, 29:313-319.

35. Francis LA, Lee Y, Birch LL: Parental weight status and girls' television viewing, snacking and body mass indexes. Obes Res 2003, 11:143-151.

36. Leech RM, McNaughton SA, Timperio A: The clustering of diet, physical activity and sedentary behavior in children and adolescents: a review. Int J Behav Nutr Phys Act 2014, 11:4.

37. Saunders TJ, Tremblay MS, Mathieu ME, Henderson M, O'Laughlin J, Tremblay A, Chaput JP: Associations of sedentary behavior sedentary bouts and breaks in sedentary time with cardiometabolic risk in children with a family history of obesity. PLoS One 2013, 8:e79143.

38. Drewnowski A, Darmon N: The economics of obesity: dietary energy density and energy cost. Am J Clin Nutr 2005, 82:265-273.

39. Scacchi M Pincelli Al, Cavagnini F. Growth hormone in obesity. Int J Obes 1999, 23:260-271.

40. Günther $A L B$, Buyken $A E$, Kroke $A$ : Protein intake levels during the period of complementary feeding and early childhood and their association with BMl and body fat percentage at age 7. Am J Clin Nutri 2008, 85:1626-1633.

41. Ali AT, Crowther NJ: Factors predisposing to obesity: a review of the literature. JEMD SA 2009, 14:81-84.

doi:10.1186/1471-2458-14-320

Cite this article as: Navti et al:: Contribution of socioeconomic status, stature and birth weight to obesity in Sub-Saharan Africa: crosssectional data from primary school-age children in Cameroon. BMC Public Health 2014 14:320 